\title{
PRINCIPLED PRAGMATISM, OR WELL-GROUNDED ECLECTICISM: A NEW PARADIGM IN TEACHING ENGLISH AS A FOREIGN LANGUAGE AT UKRAINIAN TERTIARY SCHOOLS?
}

\author{
Oleg Tarnopolsky \\ Alfred Nobel University, Dnipro, Ukraine \\ otarnopolsky@ukr.net
}

\begin{abstract}
The article discusses the ways of introducing Kumaravadivelu's (2003) principled pragmatism (or well-grounded eclecticism in the terminology of the author of the article) approach into teaching English as a foreign language for professional purposes at tertiary schools in Ukraine. Such pragmatism/eclecticism in the conditions under consideration creates opportunities for adopting different methods of teaching and learning taken from different, often contradictory, methodological approaches, as well as opportunities for uniting those methods into an organic unity, a new single approach contributing to the overall improvement of the teaching/learning process. Interpreting the difference between approaches and methods in accordance with the ideas of Richards and Rogers (1986) and treating methods as practical procedures through which an approach is implemented, the author demonstrates that a novel principled pragmatism/well-grounded eclecticism approach in teaching English at Ukrainian tertiary schools may be developed as the combination of five methods including content-based instruction, interculturalism in language studies, constructivism in language learning achieved through experiential-interactive learning procedures, blended language learning as a balanced organic unity of students' off-line and online learning experiences and balanced use of communicative learning activities and non-communicative language exercises. The research shows that the listed five methods in their unity not only form a new single approach but also fully meet the ten Kumaravadivelu's principles making that approach a clear-cut case of principled pragmatism. The concluding part of the article manifests the suggested approach as representing a possible new paradigm in teaching English for professional purposes.
\end{abstract}

Keywords: tertiary schools; principled pragmatism; well-grounded eclecticism; teaching/learning English as a foreign language; content-based instruction; interculturalism in language studies; constructivism; experiential-interactive learning procedures; blended language learning; communicative learning activities; non-communicative language exercises.

\section{Introduction}

Since Kumaravadivelu (2003) declared the advent of "post-method era" in foreign language teaching and learning, one of the principal ways of developing and improving such teaching and learning has been lying in the domain of elaborating the "principled pragmatism" approach, also first suggested by the abovementioned author. In fact, principled pragmatism may be interpreted as the concept based on the belief that: a) there is no best method, every existing method can contribute something useful to second/foreign language classroom practice; b) there should be no artificial dichotomy between language teaching/learning theory and language teaching/learning practice; c) because of that, practical teacher's beliefs, reasoning and cognition, and not scholarly constructs, are crucial in shaping the content of everyday language teaching and learning and the ways of implementing such teaching and learning (Kumaravadivelu, 2001; 2003). This means that a practical language teacher and a researcher in the area of second/foreign language teaching should 1) preferably be one and the same person and 2) this person should be able to adopt different methods in practical language teaching, even if they belong to opposing methodological approaches - but only if such methods can organically combine and complement each other in teaching practice enhancing its efficiency. It means that a certain kind of methodological eclecticism is postulated as the basis for classroom language teaching practice but only such a kind of eclecticism where different methods of teaching and learning taken from different, often contradictory, methodological approaches can be united by the teacher into an organic unity contributing to the overall improvement of the teaching/learning process. Only this can make the eclecticism well-grounded, i.e. principled ("principled pragmatism"), and Kumaravadivelu developed the ten principles that should be strictly observed while elaborating the teaching practice based on the principled pragmatism/well-grounded eclecticism approach. They include the principles of:

1. Maximising learning opportunities;

2. Minimising perceptual mismatches;

3. Facilitating negotiated interaction;

4. Promoting learner autonomy;

5. Fostering language awareness;

6. Activating intuitive heuristics;

7. Contextualising linguistic input;

8. Integrating language skills;

9. Ensuring social relevance; 
10. Raising cultural consciousness (Kumaravadivelu, 2003).

Regretfully, the "principled pragmatism" (or "well-grounded eclecticism" in our interpretation) theory, immensely popular among language teaching professionals in the USA and even taught at universities to future ESOL teachers, is very little known in Ukraine and, therefore, has little or no impact on teaching English as a foreign language at Ukrainian secondary and tertiary schools. The goal of this article is the discussion of the ways of applying the principled pragmatism/well-grounded eclecticism approach to teaching English to university students in Ukraine who study that language for professional purposes. Such ways are considered through analysing some methods from different approaches that can be organically and effectively combined (well-grounded eclecticism) for improving the English language teaching/learning process and making that process better suited to achieving the professionally-oriented foreign language learning goals.

\section{Results and Discussion}

\subsection{Content-based instruction as the first constituent method in the principled pragmatic approach to teaching English for professional purposes}

Content-based instruction (Stoller, 2007), first substantiated by Brinton, Snow and Wesche (1989) and now recognised in the developed countries as the fundamental method in teaching ESP - English for Specific Purposes or for professional purposes, provides for “... the integration of content from the subjects of students' majors with the goals of target language teaching. It ensures parallel acquisition of knowledge from certain non-linguistic disciplines together with the acquisition of the target language and the skills of communicating in it. In such instruction, the ESP curriculum is most closely linked or even based on the curricula of one or several of students' majoring disciplines so that learning the target language content follows the requirements of learning some professional content from the majoring disciplines through the medium of the target language. The development of students' target language communication skills proceeds mostly subconsciously through their learning in the target language the content matter from the majoring subjects. In this way, content-based instruction eliminates the gap between language learning and learning professional subjects ensuring students' learning the latter through the medium of the former." (Tarnopolsky, 2012, p. 73)

Such characteristics of content-based instruction naturally make it an obligatory integral part of English language training at institutions of higher learning because no other method can better serve the future students' professional orientation in their language studies. Moreover, a number of authors (Stoller, 2007; Tarnopolsky, 2012) believe that content-based instruction in university ESP courses is the major stepping stone to introducing English immersion (teaching courses of professional and other non-linguistic subjects through the medium of the target language - Johnson and Swaine, 1997) which is considered to be the highest and the most efficient form of ESP teaching from the point of view of meeting the professional requirements to such teaching.

It should be noted that content-based instruction does not focus only on the specific kind of ESP that reflects the students' major (for instance, only on English for engineering when training technology students or English for oil and gas industries for students of the relevant major). In today's conditions, Ukrainian university students of all majors should also acquire some fundamental mastery of EAP - English for Academic Purposes (Alexander, Argent, Spencer, 2008) as a specific part of ESP. Without that part, ensuring learners' international mobility becomes impossible because for studying during a semester or an academic year at a university abroad, the acquisition of EAP is one of the fundamental requirements. Thus, only content-based instruction in English covering the content-matter of students' majoring disciplines and including learners' mastering of EAP as a target language for doing their international (outside-Ukraine) studies can guarantee the minimum language prerequisites for learners' international mobility during the years of their university training.

Besides, in the majority of professionally-oriented university courses of English content-based instruction also presupposes the inclusion of at least the basics of Business English (Frendo, 2005). The students of all majors learning English for professional purposes learn it for their future international professional activities. Such activities almost always include business relationships with foreign partners and those relationships require communication using Business English (Goddard, 2007).

Therefore, the analysed first constituent method of the principled pragmatic approach to teaching English for professional purposes at Ukrainian tertiary schools turns the ESP course into one of the courses of professional training preparing students not only for purposeful and multi-faceted use of English in their future professional activities but also giving them opportunities for international academic mobility while still studying at their university and, after graduating from it, for establishing and maintaining business relationships with potential professional foreign partners. 


\subsection{Interculturalism in studying English as a foreign language as the second constituent method in the} principled pragmatic approach to teaching English for professional purposes

The communicative approach to foreign language teaching still reigns supreme in all ESP courses taught at higher schools both in Ukraine and in other countries of the world. However, in the last ten or even fifteen years more and more scholars speak about "the post-communicative era" in English language training. Communicative language learning (CLL) started to be regarded as something to be replaced with the intercultural method (IM) allowing students to learn how to communicate in English efficiently with representatives of different cultures without breaking the sociocultural norms characteristic of a given culture and in this way attaining communicators' specific pragmatic goals (Ferradas, 2010). As it has been shown in one of our articles (Tarnopolsky, 2010), this opposition of CLL and IM is methodologically incorrect because the former is responsible for the ways of teaching English as a foreign language while the latter is in charge of the selection of content for that teaching - thus not only not being in opposition to each other but even being mutually complementary.

For instance, when we follow the intercultural method, we focus more on developing students' sociolinguistic and pragmatic competences (especially if we teach English to solve some specific pragmatic or professional tasks, as in ESP, especially, in Business English) and pay less attention to their linguistic competence. But we can never totally ignore any of the three competences mentioned above even if we state that our principal goal is teaching English for intercultural communication. Whatever is our final goal in university students' language studies, in all cases we teach learners to communicate efficiently enough to attain through that communication their pragmatic goals without breaking any of the important linguistic, sociolinguistic and cultural norms that come into play in every particular communicative event. And how can we teach such communication without CLL that, roughly speaking, is nothing else but teaching communication for communication through and in communication? Of course, if we focus on intercultural aspects of communication in English, we may neglect to a certain extent some standard English grammar and pronunciation in our teaching. But it does not compromise CLL in any way - that CLL which has never emphasised grammar or phonetics. So, there are no grounds for speaking about the post-communicative era.

However, even if we still continue living in the communicative era, we can in no way neglect the necessity of immersing our ESP students into target language culture. It concerns not the culture with a big " $\mathrm{C}$ " (literature, art, law, political structure, etc.) but the culture with a small "c" - those culturally and socially conditioned patterns of behaviour in communication that make such behaviour culturally and socially acceptable for native speakers. The acquisition of such patterns is especially important when English is being learnt for professional purposes because in international professional (particularly, business) intercourse neglecting those patterns is hardly ever tolerated by foreign partners so that such neglect can even result in failure of international collaboration, which otherwise could be quite successful and fruitful (Gibson, 2002).

It should be noted that in university ESP courses intercultural studies should not be limited to acquiring culturally and socially conditioned patterns of behaviour in communication that are characteristic of Englishspeaking professional communities only. Students also need to learn those cultural patterns that characterise other communities of professionals whose native language is not English but whose representatives will negotiate in English on the matters of common professional interest with their Ukrainian counterparts. For instance, students should be taught how not to break the social and cultural norms important for native speakers of Chinese or Japanese when communicating with them in English on professional issues.

So, the second constituent method of the principled pragmatic approach to teaching English for professional purposes at Ukrainian tertiary schools turns the ESP course into a course of intercultural training preparing students for becoming socially and culturally acceptable on the international professional arena when solving their professional problems through communication in English while being active on that arena.

\subsection{Constructivism achieved through experiential-interactive learning procedures as the third constituent method in the principled pragmatic approach to teaching English for professional purposes}

If the first two methods discussed above mostly concern the ways of selecting and forming the content of teaching, the last three of them analysed in this and the following two sections of the article are focused on the ways of organising and implementing learning.

The first and the most important of them - the constructivist method (Glaserfeld, 1995; Richardson, 2003) - was not developed for language teaching. In teaching other subjects, especially in different university courses, it was considered as a way of " ... providing students with opportunities of "constructing" their own knowledge and skills through practical experience in real-life or modelled activities. In this case, students acquire their knowledge and skills as a by-product of their real-life or modelled activities, thus internalising (appropriating) the knowledge and skills and not just learning them" (Tarnopolsky, 2012, p. 13). 
Constructivism has only comparatively recently entered the domain of foreign language education and has been put into practice there through the so-called experiential learning (Kohonen, et al, 2014; Tarnopolsky, 2012). When teaching English for professional purposes, experiential learning presupposes such an organisation of the teaching/learning process which gives opportunities of constantly modelling the future specialists' professional activities in their language learning activities, so that the latter model the professional communication. The important point is that such quasi-professional communication is implemented not by the means of learners' L1 but by the means of their target language, thus creating opportunities for acquiring the foreign language and communication skills mostly involuntarily and subconsciously as a by-product of modelled quasi-professional activities and quasi-professional L2 communication.

In the works by Tarnopolsky (2012 and a number of others), it has been demonstrated that experiential learning when teaching English for professional purposes at Ukrainian tertiary schools means designing the teaching/learning process as an uninterrupted succession of professionally-oriented role plays and simulations, students' brainstorming, case studies, discussions, presentations, learning projects, writing professional essays, abstracts, summaries, etc. in the target language. All those activities are constantly accompanied by learners' autonomous search for information in the target language (mostly on professional Internet sites in English - see the next section) and by processing the information found through reading and listening with the aim of providing sufficient professional data required for doing all the profession-oriented creative learning tasks indicated above. In the works mentioned at the beginning of this paragraph, it has also been demonstrated that in the conditions under consideration experiential learning necessarily needs to be experiential-interactive. The interactive component in this case means that, while doing most experiential learning activities, students, working in pairs and small groups, constantly interact in the target language both among themselves and with the outside professional target language environment/outside professional target language sources of information (e.g., professional Internet resources for obtaining the data required for doing profession-oriented experiential learning tasks - see above). Such an interaction is an absolute must in view of the creative and difficult nature of learning tasks because, for achieving success, learners should positively influence and help each other in their learning efforts (cooperative learning achieved through interaction) and be positively influenced and helped by the support they get from finding relevant information in outside professional target language sources. As a result, the learning process gets additional social regulation and social orientation.

Everything said in this section shows how closely and organically constructivism achieved through experiential-interactive learning procedures is intertwined with content-based instruction. The latter provides for the professional content of language studies making them dependent on students' major, while the former provides for the profession (major)-oriented nature of all the learning activities thus ensuring learners' proper acquisition of the professional content processed in those activities through the means of the target language. The same may be said about interculturalism because it provides for professionally-oriented cultural studies being organically included in the professionally-oriented learning content and implemented through professionally-oriented experiential learning activities.

\subsection{Blended language learning as the fourth constituent method in the principled pragmatic approach to teaching English for professional purposes}

The preceding section strongly emphasised the importance of students' conducting Internet search on professional sites in English for collecting information required for doing their creative experiential learning tasks. This Internet search is supposed to become a regular feature of ESP courses both in learners' in-class and out-of-class work. But the Internet can and should be used by ESP students not only for finding relevant and required information in English (Harmer, 2001, p. 146). It can also be the source of student(s)-student(s) and teacher-student(s) communication in English via the Internet, including into that communication doing on-line learning projects both within one and the same university and inter-university projects involving even students from different countries. No less possible is publication of students' works in the Internet network. The latter leads to creating learners' own web-pages in English with the best students' works, such as essays, published there. It can even lead to publishing students' online journals in English, which makes their English studies much more motivated uniting all learning efforts in the framework of one meaningful and creative communicative activity (Warschauer, Shetzer, Meloni, 2000).

If online work becomes a regular feature of English language studies, those studies turn into blended ones (Sharma, Barrett, 2007). They unify traditional classroom learning and online learning thus creating a flexible learning environment which greatly helps to intensify and facilitate practical language training. There is no need to explain how well such blended learning matches experiential-interactive learning activities and, in general, constructivism in language teaching becoming a harmonious integral part of the constructivist/experiential learning process. It even more harmoniously and organically matches content- 
based instruction and interculturalism because it is to a great extent from the Internet that students obtain information that makes their studies content-based and culture-oriented.

\subsection{Balanced combination of communicative learning activities and non-communicative language exercises as the fifth constituent method in the principled pragmatic approach to teaching English for professional purposes}

In section 2.2. of this part of the article the absolute dominance of the communicative approach (CLL) in today's foreign language teaching has already been emphasised. There is no need to prove additionally that the four constituents of the principled pragmatic approach suggested by us lie within the domain of CLL. Contentbased instruction presupposes students' acquisition of the content of majoring disciplines through target language communication. In section 2.2. the link between cultural studies (IM) and CLL has already been established. All experiential-interactive learning activities are communicative by their very nature and cannot be any other. Finally, online learning activities presuppose communication via the Internet (see the preceding section).

All this seems to exclude non-communicative language exercises as something opposite to the fundamental postulates of the communicative approach. However, hardly any textbook for English language learning (and especially workbooks for learners' home tasks) has none them. This is not surprising because they are very useful in some respects. First, some researchers (Ellis, 1990; Fotos, 1994) rightfully claim that language acquisition is more effective with some degree of focusing on language forms for achieving consciousness-raising as to those forms (and non-communicative language exercises do just that). Second, it cannot be doubted that such exercises reinforce lexical, grammatical and pronunciation items acquired communicatively due to the above-mentioned language form-focusing (some pronunciation and lexical items simply cannot be remembered and learnt without such focusing). Third, one of our experimental studies done more than three decades ago (Tarnopolsky, 1987) convincingly proved that a very limited number ( 2 or 3 ) of non-communicative exercises done immediately after introducing some new language (grammar) material had substantially reduced students' language errors when using that material in their oral speech.

All this calls for some legitimising of non-communicative language exercises in the principled pragmatic approach based on CLL. The question is how and where to use them. First, their number should be really limited in comparison with communicative learning activities - hardly more than 10-15\% of all learning activities in the language course. This is enough for reinforcing the language material and students' consciousness-raising as to it (language awareness) but cannot compromise the overall communicative orientation and nature of the language course. Second, the place for doing such exercises is outside the English language classroom (students' home tasks), so that they make no contradiction and do not place themselves in opposition to the exclusively communicative (experiential-interactive) learning activities done in that classroom. In such conditions, communicative learning activities and non-communicative exercises can be combined quite harmoniously, in no way contradicting one another or becoming an obstacle to each other.

\subsection{Correspondence of the constituent methods of the suggested approach to Kumaravadivelu's principles}

Everything said in the preceding sections shows how well the suggested constituent methods match and even complement one another, all merging in one and the same harmoniously unified approach. This approach is doubtlessly eclectic because the constituent methods are taken from different other approaches - sometimes even opposing each other (see the preceding section 2.5.). Therefore, it should be demonstrated in this article that the eclecticism is well-grounded, i.e. matching the ten principles put forward by Kumaravadivelu. Only such a demonstration can prove that our approach is indeed the principled pragmatic one.

There can hardly be any objections to the statement that content-based instruction, interculturalism, experiential-interactive (constructivist) and blended learning maximise learning opportunities (the first principle - see Introduction). It is so because learning the target language through the content of learners' majoring disciplines and the target culture, as well as implementing such learning through students' selfconstructing their own target language knowledge and skills with the help of online resources create an enormous and almost limitless number of such opportunities.

Constructivist (experiential-interactive) and blended learning also minimise perceptual mismatches (the second principle). Such mismatches mean the discrepancies between teacher's intentions and student's interpretations of those intentions so that those discrepancies can cause the learning outcomes unexpected and undesirable for both sides. But if learning is constructivist (experiential-interactive) and blended, it is totally learner-centred because students are to a great extent "teaching themselves," leaving few opportunities for the emergence of perceptual mismatches.

Constructivist (experiential-interactive) learning also facilitates negotiated interaction (the third principle) since it is designed as totally interactive in nature. Besides, together with blended learning, it 
promotes learner autonomy (the fourth principle) to the utmost because self-constructing one's own target language knowledge and skills with the help of online resources are necessarily more autonomous than any other kind of learning.

In the presence of a harmonious combination of communicative learning activities and noncommunicative language exercises specifically used to enhance learners' language awareness, the fifth principle (fostering language awareness) is implemented practically automatically. The same concerns activating intuitive heuristics (the sixth principle) because self-constructing knowledge and skills through experiential-interactive activities inevitable automatically activates those heuristics due to the fact that learning involves not only mostly intuitive and subconscious target language acquisition but also acquisition of the content of majoring disciplines and target culture by way of doing creative tasks that are heuristics-oriented.

In the conditions where the instruction is content-based and culture-oriented, the linguistic input can be only contextualised (the seventh principle) because it is never supplied outside the context of professional (majoring disciplines) and cultural context.

Experiential-interactive learning activities always integrate language skills (the eighth principle). Moreover, such integration was even put forward as one of the leading principles of their organisation (Tarnopolsky, 2012, pp. 176-180). A good example can be found in learning projects that always begin with brainstorming and discussions (speaking and listening), continue with collecting written and oral information through reading and listening, proceed to discuss that information as well as the specific ways of completing the project task (speaking and listening), then pass on to actually completing that task mostly in the written form (writing) and finish with discussing the results (speaking and listening). Besides, those results are sometimes in need of being changed by way of re-writing the final project product (writing).

In what concerns the ninth principle (ensuring social relevance), it has already been indicated in section 2.3. that the interactive component in students' English language studies makes it possible for them to positively influence and help each other in their learning efforts and to be positively influenced and helped by the information found in outside professional target language sources. This provides for the social regulation and social orientation. Besides, the content-based and culture-oriented instruction also makes learning socially relevant linking language acquisition to students' gaining command of their future profession and to their acquiring knowledge of other nations' cultures.

Finally, interculturalism as the constituent method of the suggested approach doubtlessly makes the tenth principle (raising cultural consciousness) fully implemented.

In this way, it can be safely assumed that, since all the ten principles underlying principled pragmatism are fully met, the suggested approach to teaching English as a foreign language at Ukrainian tertiary schools can be safely claimed to be a principled pragmatic one and the eclecticism embodied in it can be considered as well-grounded.

\section{Conclusions}

Everything said in this article leads to the conclusion that in teaching English for professional purposes at tertiary schools it is quite possible to organise the teaching/learning process on the basis of the principled pragmatic approach advocated by Kumaravadivelu (2003). This approach in our case (as it will be in most other similar cases) is necessarily eclectic being formed out of five constituent methods: content-based instruction, interculturalism in language studies, constructivism in language learning achieved through experiential-interactive learning procedures, blended language learning and balanced combination of communicative learning activities and non-communicative language exercises. All these methods belong to different approaches: content-based instruction belongs to the approach whose essence is in trying and merging language studies and professional studies in higher education; interculturalism represents the culture-oriented approach to language studies; constructivism embodies the approach aimed at attaining students' autonomy in language acquisition by using learning activities modelling real-life ones; blended learning implements the approach based on applying information technologies for improving language learning. Finally, a balanced combination of communicative learning activities and non-communicative language exercises unites two opposing approaches: communicative language instruction and traditional form-focused language teaching.

The most important thing clearly demonstrated in the article is that, despite belonging to different approaches (even mutually contradictory ones as in the case of the last constituent method), all the five suggested constituent methods seamlessly merge forming a new unity, i.e. a novel approach to teaching English for professional purposes at tertiary schools. It means that in the situation under consideration the eclecticism is very well grounded. Moreover, as it has been shown in the last section of the preceding part of the article, the suggested approach fully meets all the ten of Kumaravadivelu's principles (2003) making it a 
clear-cut case of a fully principled pragmatic approach to teaching English for professional purposes. The fact that is so is also confirmed by teaching practice. During the years of developing this approach, five coursebooks (each consisting of a student's book, workbook, teacher's book and audio materials) for teaching English to university students of different majors have been developed by several creative teams with the author of this article as the leading author, scientific and general editor of all the coursebooks. They include: a coursebook for students majoring in Economics and Business "Business Projects" (2002 and 2007); a coursebook for students majoring in Psychology "Psychological Matters" (2011); a coursebook for students majoring in Pedagogy "Pedagogical Matters" (2015); a coursebook for first-year students majoring in Technology and Economics "Professional Basics" (2016) and a coursebook for students majoring in Tourism and Hospitality "Tourism and Hospitality Industry Matters" (2018). All the coursebooks listed above have been used with very positive learning outcomes in courses of English for professional purposes at least at one but mostly at several Ukrainian universities since the year of their publication and until today. All of them were designed following the suggested approach and their overall success confirmed by the teachers and the students who were using them testifies to the soundness of that approach.

Most certainly, the suggested five constituent methods are not the only ones that can be used to form a new principled pragmatic approach well-grounded in its eclecticism. Other similar approaches can be developed for different types of educational institutions, those approaches being equally pragmatic and eclectic in a principled and well-grounded manner but based not only on the above discussed constituent methods but also on some other ones. The importance of our research and our assumptions, as we see that importance, lies in the fact that they are the first of their kind and ground-breaking in what concerns the introduction of principled pragmatism/well-grounded eclecticism into foreign language teaching at tertiary schools. Thus, they open up a kind of new paradigm for such teaching, a paradigm based not on one language teaching theory but on adopting what is good for teaching practice from a number of them, uniting those borrowings from many approaches into a single new principled pragmatic approach better suited to the needs of the pedagogical practice.

\section{References:}

Andarab, M.S., Büyükyazi, M. (2013). Mismatches between teacher intention and learner interpretation; significance of non-native speaker teacher of English. Journal of Education and Practice, 4 (4), 30-37.

Brinton, D.M., Snow, M.A., \& Wesche, M.B. (1989). Content-based second language instruction. New York: Newbury House Publishers.

Ellis, R. (1990). Instructed second language acquisition: Learning in the classroom. Oxford: Basil Blackwell.

Ferradas, C.M. (2010). Plenary: Outside looking in: intercultural and intermedial encounters in ELT. In Briony Beaven (Ed.) IATEFL 2009 Cardiff conference selections (pp. 16-20). Canterbury, Kent: IATEFL.

Fotos, S.S. (1994). Integrating grammar instruction and communicative language use through grammar consciousness-raising tasks. TESOL Quarterly, 28(2), 323-351. https://doi.org/10.2307/3587436

Frendo, E. (2005). How to teach Business English. Harlow, Essex: Pearson Education Limited.

Alexander, O., Argent, S., \& Spencer, J. (2008). EAP essentials. A teacher's guide to principles and practices. Reading: Garnet Publishing Ltd.

Gibson, R. (2002). Intercultural business communication. Oxford: Oxford University Press.

Glaserfeld, E. von (1995). A constructivist approach to teaching. In L.P. Steffe, J. Gale (Eds.). Constructivism in education (pp. 316). New Jersey: Lawrence Erlbaum.

Goddard, R.J. (2007). Teaching English for international business. Sandy Bedfordshire: Authors OnLine Ltd.

Harmer, J. (2001). The practice of English language teaching (3d ed.). Harlow, Essex: Longman.

Johnson, R.K., \& Swain, M. (1997). Immersion education: International perspectives. Cambridge: Cambridge University Press. https://doi.org/10.1017/CBO9781139524667

Kohonen, V., Jaatinen, R., Kaikkonen, P., \& Lehtovaara, J. (2014). Experiential learning in foreign language education. NY: Routledge. Kumaravadivelu, B. (2001). Toward a postmethod pedagogy. TESOL Quarterly, 35 (4), 537-560. https://doi.org/10.2307/3588427

Kumaravadivelu, B. (2003). Beyond methods: Macrostrategies in language teaching. New Haven and London: Yale University Press.

Richards, J.C. \& Rogers, T.C. (1986). Approaches and methods in language teaching: A description and analysis. Cambridge: Cambridge University Press.

Richardson, V. (2003). Constructivist pedagogy. Teachers College Record, 105 (9), 1623-1640. https://doi.org/10.1046/j.14679620.2003.00303.x

Sharma, P. \& Barrett, B. (2007). Blended learning. Using technology in and beyond the language classroom. Oxford: Macmillan.

Stoller, F.L. (2007). Content-based instruction. In Nelleke van Deusen-Scholl and Nancy H. Hornberger (Eds), Encyclopedia of language and education. Vol.4: Second and foreign language education (pp. 59-70). New York, NY: Springer.

Tarnopolsky, O.B. (1987). Profilaktika grammaticheskih oshibok v jekspressivnoj ustnoj rechi [Prophylaxis of grammar errors in expressive oral speech]. Inostrannye jazyki v vysshej shkole, 20,72-79. Moscow: Vysshaja shkola.

Tarnopolsky, O. (2010). Must the Intercultural Approach, EIL and ELF oust CLL? IATEFL Voices, 217, 5-6.

Tarnopolsky, (2012). Constructivist blended learning approach to teaching English for specific purposes. London: Versita. https://doi.org/10.2478/9788376560014

Warschauer, M., Shetzer, H., \& Meloni, C. (2000). Internet for English teaching. Alexandria, VA: TESOL. 